\title{
Sustaining the Ivory Tower: \\ Oxbridge Formal Dining as Organizational Ritual
}

This article was published in the

JOURNAL OF MANAGEMENT INQUIRY, 2009, 18 (4), pp. 326-343.

doi: $\underline{10.1177 / 1056492609336482}$

Nontraditional Research section

Authors' Details:

MariaLaura Di Domenico

Surrey Business School,

University of Surrey

Guildford GU2 7XH

United Kingdom

Nelson Phillips

Tanaka Business School

Imperial College London

South Kensington Campus

London SW7 2AZ

United Kingdom 


\section{Sustaining the Ivory Tower: Oxbridge Formal Dining as Organizational Ritual}

In this ethnographic study of formal hall ritual in Oxbridge Colleges, the authors show how this special form of dining plays a key role in organizational cohesion, demarcation and continuity. Formal hall serves as a central organizing principle of the colleges, having social, political and pedagogic facets. Drawing upon participant observation of 22 formal dinners, this article explores its significance on different levels. It examines how formal hall creates social stability, provides historical continuity, reaffirms hierarchy and bureaucratic order, perpetuates exclusivity and reverence, and provides college level space for organizational politicking, relationship-building and information exchange. It also cements important stakeholder relations at broader societal levels. Furthermore, these outcomes feed into its overriding purpose of solidifying shared elite identity through selective membership and participation. Transgressions against this elitist formal dining ritual are also addressed, being conceptualized on a continuum from 'higher order' to 'lower order' according to degree of potential threat to the ritual. The authors conclude with a discussion of their findings' implications for research on organizational ritual, whereby inclusion, exclusion and identity issues lie at the heart of the ritual's power over organizational processes, and the social control of actors not solely within but also beyond immediate organizational boundaries.

KEYWORDS: college, food, formal dining, organizational ritual, Oxbridge, university 
"It was a fine Feast...There was Caviar and Soupe à l'Oignon, Turbot au Champagne, Swan stuffed with Widgeon, and finally, in memory of the Founder, Beefsteak from an ox roasted whole in the great fireplace of the College Hall ... For two hours the members of Porterhouse were lost to the world, immersed in an ancient ritual that spanned the centuries" (Tom Sharpe 'Porterhouse Blue' pp.1-2).

In this satirical account of communal formal dining at an imaginary Oxbridge ${ }^{1}$ college, Tom Sharpe vividly depicts a scene of ritual feasting still regularly enacted. In this article, we explore this event and its role in organizational processes. Our overarching aim is to examine dining rituals and ceremonies within organizations, and between organizations and wider society. We use insights from sociological and organizational literature on ritual, food and eating, to examine the routine college dining event of 'formal hall' ${ }^{2}$ as an example of organizational ritual. Influenced mainly by the agonistic thesis of ritual, our analysis centers upon formal hall's role in maintaining key college organizational mechanisms. Drawing upon an ethnographic study, we explain the evolution and conventions, as well as corresponding effects and transgressions, in its staging.

Our key contribution is to demonstrate the importance of formal dining as a symbolic medium reaffirming social structure, order and interaction. Formal hall ritual plays a central and complex role in Oxbridge's organizational fabric. Evidence from our study extends existing research by exploring the event's significance on two levels. Firstly, within the organization it increases social cohesion, provides historical continuity, reaffirms hierarchies, perpetuates exclusivity, and provides space for politicking, relationship-building and information-exchange. Secondly, as integral to the collegiate model, it cements important stakeholder relations at broader societal levels. However, these outcomes are imbued with transgressions causing variations and ambiguities which can subvert this elitist ritual's cohesive effects. Its overall power lies in its ability to continually neutralize threats.

Few organizational studies have specifically focused upon formal dining within organizations, although more have examined social events involving conspicuous 3

Di Domenico, M. \& Phillips, N. (2009) 'Sustaining the Ivory Tower: Oxbridge Formal Dining as Organizational Ritual'. Journal of Management Inquiry, 18 (4), pp. 326-343. doi: $\underline{10.1177 / 1056492609336482}$ 
consumption of food and drink such as business dinners, Christmas parties, 'nights out', and training events (e.g. Rosen, 1985, 1988; Sturdy, Schwarz, \& Spicer, 2006). We extend existing work by embracing sociological perspectives, thereby showing that formal hall is elite enactment par excellence. We argue that dining rituals are significant for organizational life despite their complex, often-contested nature. Furthermore, their effects extend to inter-organizational and societal levels.

Our argument has four parts. We position our analysis by discussing ritual's organizational symbolism, before moving to our research setting and methodological approach. We then present our findings, structuring our arguments around an examination of formal hall both within the college setting and in the broader context of relations with stakeholders, including consideration of evident transgressions against the ritual. In conclusion, we discuss our research's implications for understanding organizational rituals, especially around food, drink and their consumption.

\section{RITUAL THEORY AND SYMBOLIC DISPLAY: FOOD AND CONSUMPTION}

Our arguments are positioned within existing literature in organization theory and sociology. We initially consider various approaches to ritual, positioning our arguments and theorizing to frame subsequent data interpretations and conclusions. We then consider the literature on food consumption as ritualized symbolic practice, and embed our focus on institutionalized formal dining within a critique of ritual's class-based importance. Our subsequent discussion explores ritual and consumption within organizational contexts, developing insights from studies using dining as a lens through which ritualized organizational practices are analyzed.

\section{Deconstructing Ritual}

Organizational literature reveals various definitions of 'ritual', 'ceremony' and 'rite'. Rook (1985) defines 'ritual' as encapsulating both everyday and extraordinary 
experiences, arguing that "a ritual is a larger, plural experience while habits tend to be singular behaviors ..." (p.252). Beyer \& Trice (1987) and Trice, Belasco, \& Alutto (1969) link rituals to rites and ceremonies. Rites or ceremonials contain ritualistic behaviors being "relatively elaborate, dramatic, planned sets of activities that consolidate various forms of cultural expressions into one event..." (Trice and Beyer, 1984, p.655). Although our focus on formal hall fits these definitions, such typologizing is fraught with epistemological representational difficulties, generally lacking appreciation of contextual dynamics (Rosen, 1988, p.464).

Following Rosen, we adopt an inclusive definition of ritual as overlapping ceremony and rite. It holds special significance for participants and audience, essentially constituting planned sequential activities comprising a repeated social event or drama, held either routinely or infrequently (Pettigrew, 1979), whereby the script describes event sequences enacted in the performance. Its degree of rigidity, or openness to alteration, depends on the ritual's nature (e.g. religious, celebratory) and audience. Other facets of ritual structure include artifacts (Rook, 1985, p.253), symbolic ritual displays such as ceremonial attire or food and drink items.

There is little agreement about ritual's theoretical significance. One literature strand stems from Durkheim's functionalist perspective, viewing ritual as creating social order through collective action and participation in routine customs and traditions (Durkheim, 1965; orig., 1915). Thus rituals unite people in common purpose and belief, encouraging social solidarity through following prescribed conduct and shared routines while exchanging recognized symbols. Their power as spectacle often generates euphoric sentiments. A second related literature strand views ritual as manifestation of shared understandings of social reality. This perspective focuses on shared meanings and approaches ritual as expressing collectively defined social definitions and benchmarked representations of reality, enabling order and routine while permitting the development of mechanisms to cope with social change (Bell, 1997; Turner, 1969). However, neither approach sufficiently explains the complex power dynamics at play and transgressions that may threaten the ritual. Neo-Marxist critiques of functionalism (e.g. Anand \& Watson, 2004, p.61) argue that ritual imparts 
manipulative or coercive domination systems, with power politics at the heart of these processes. This agonistic thesis (Roth, 1995) allows for stratification of agents, whereby core elite organizational members demonstrate their power and authority through exclusive rituals, while peripheral or excluded members attempt to counter, subvert or endear themselves to this power locus (Lukes, 1975).

We build on elements from all these perspectives. However, mainly following the agonistic view, we wish to unearth and critique the complex dynamics of the ritual and the transgressions that affect it. The central role of power in imparting systems of inclusion and exclusion which can subvert, distort or even support the ritual's enactment is important in understanding the ritual's effects and orchestration. These facets are not sufficiently encapsulated by the 'functionalist' or 'shared meaning' readings of ritual. For us, the more critical and multi-dimensional stance of the agonistic thesis is most useful in delineating our exploration of ritual's roles and effects. However, the agonistic approach remains limited in the existing body of work considering food and consumption per se, and more markedly in its specific appreciation of organizational contexts. This is an evident conceptual gap.

In order to build upon our theorizing, we now consider pertinent literature on food consumption as ritualized symbolic practice, including class-related protocols which relate to issues of privilege, power and esteem. Literature on organizational ritual is then explored. Combined, they contribute to the theoretical contextualization of the data and findings.

\section{Food Consumption as Ritualized Symbolic Elements}

Literature on food consumption and society often focuses on class and symbolic display. In The Civilizing Process (1969; orig., 1939), Elias analyses large social structures and individual agency by critiquing social attitudes and etiquette standards, illustrating how the emergence of complex social relations moulds self-perceptions and behavioral conformity. Eating and drinking are not merely consumption acts but 
important forms of expression, communicating socially-shared meanings about rituals relating to time, seasons and social status (Douglas \& Isherwood, 1979).

Bourdieu's (1984) work adopts a predominantly Marxist-structuralist approach, arguing that symbolic capital is yielded through particular consumption patterns. Those with high levels of symbolic capital, governed by social class, lifestyle and occupation, construct notions of 'good' or 'poor' taste. Thus, the embodiment and display of habitus gives rise to distinctions between social actors possessing varying amounts of symbolic capital. This creates a societal hierarchy of taste, revealing the true dilettante while exposing the parvenu.

Other works similarly explore class and social status as manifest symbolic elements of consumption through the lens of food, drink or dining (Beardsworth \& Keil, 1997; Finkelstein, 1989; Goody, 1982; Gronow, 1997; Roseberry, 1996; Walton, 1990; Warde \& Martens, 2000). Outside the public arena, Marshall (2005) and Visser (1993) examine cultural ideals of eating 'properly' as codified into conventional family meal rituals, whereby adherence to customs, decorum and manners provide continuity of tradition. The structuralist analyses of Adair (1986), Barthes (1983; 1972) Douglas (1972) and Levi-Strauss (1969, 1966) also examine cultural symbolism in eating and drinking. Levi-Strauss' notion of 'culinary triangle', highlights how food's cultural-symbolic value, represented by its physical state of raw, cooked or rotten, informs and structures social rules and practices. In his semiological analysis of media representations of cookery as integral to the language of mass culture, Barthes (1972) also postulates that:

... just as wine becomes for a good number of intellectuals a mediumistic substance which leads them towards the original strength of nature, steak is for them a redeeming food, thanks to which they bring their intellectualism to the level of prose and exorcise, through blood and soft pulp, the sterile dryness of which they are constantly accused (p.62). 
Food, drink and dining are intrinsic to cultural events. Their integral symbolism within specific rituals, such as Thanksgiving supper (Siskind, 1992), is essential for the ritual's staging. Of particular relevance to organizational scholars is Douglas's (1986) influential work How Institutions Think, opening with an illustration of eating's symbolic importance as necessary for institutional survival, being integral to collective behavior, negotiation and decision-making.

\section{Ritual and Organizations: Food and Dining}

Analyses of food and dining rituals in organizations can be framed within broader studies of ritual within organizations. Indeed, there are interesting examples in the literature of ritual within various organizational contexts. Thus, Anand and Watson (2004) adopt an institutional theory perspective to examine the case of the Grammy Awards showing how such ceremonies act as important institutional mechanisms. Similarly, Kunda's (1992) ethnographic study analyses corporate rituals defined by the firm's power hierarchy. Rituals such as training events ensure members' conformity to organizational norms. Their powerful symbolic quality is further explored in the notion of 'excess ceremoniality' (Alvesson, \& Karreman, 2007), whereby intense symbolic display gains "credibility through being detached from operational efficiency ... standing out as something special, original, and superior" (p.718).

More specifically, there are examples of food consumption as ritualized practice within organizational analyses (see Table 1). Rosen uses the annual office Christmas party (1988) and business-breakfast meeting (1985) to illustrate ritualized social dramas. Sturdy, Schwarz, \& Spicer (2006) explore business dinners shared by clients and consultants as liminal spaces, existing in parallel with formal organizational spaces, effecting organizational changes through informal political practices embedded within shared, socially-defined dining rituals. Harris and Sutton (1986) use data collected from parties, picnics and dinners in dying organizations to theorize parting ceremonies in organizations. 


\section{INSERT TABLE 1 HERE}

Those organizational studies of meals and dining largely focus upon their significance to the organization or its members. We explore organizational ritual by adopting an analytical lens, looking not only at the intra-organizational level, but also at the interorganizational and wider societal levels. We develop a critical and mainly agonistically-informed view of Oxbridge 'formal hall', examining this routine college dining event as an intriguing example of organizational ritual to address the following research question:

What role do formal dining rituals play within organizations, between organizations, and between organizations and the wider society?

\section{RESEARCH CONTEXT AND METHODOLOGY}

\section{History and Setting}

Historically, the ancient collegiate university was a training ground for future leaders and bureaucratic elites. The college-based structure ensured enclosed systems of regulatory order and opulence, molding learned gentlemen in an intellectual tradition befitting social status and future careers. The historical origins of Oxbridge are monastic in character and design, innately bound-up with institutional malecenteredness, requiring obedience and complete commitment to established orders. Thus, in "such prestigious centres of learning as Oxford and Cambridge, celibacy was actually required for the dons until late in the 1800s" (Stiver-Lie, 1990, p.108).

For students and dons, residential colleges traditionally provided all their needs, freeing time and effort for devotion to scholarly enquiry. Through the provision of servants, accommodation, sustenance and companionship, the college almost replaced family life. Indeed, during the British Empire's height, Oxbridge Colleges trained the British elite for leadership. This collegiate model appeared desirable also for indigenous elites throughout the Empire, and was imitated when colonial universities 
were established in the mid-twentieth century. Thus, in African colonies, formal hall, high-table and other elite British practices and ceremonials were established in preindependence universities. After national independence, these were adapted further to fit elite cultural contexts (van den Berghe et al., 1973).

The twentieth century enfranchisement and gradual recognition of women posed a challenge to established Oxbridge orderings. Full degree status was withheld from women students until 1920 in Oxford and 1947 in Cambridge. They had previously been unable 'to call themselves 'undergraduates' because they were not formally admitted to university membership on the same terms as men" (Aziz, 1990, p. 33), embodying opposition to the institutions' ecclesiastically-based goals and traditions. However, female students and faculty members eventually became more visible, integrating into ancient colleges and their rituals. Indeed, several female-only colleges were established and prospered, although most colleges are now co-educational ${ }^{3}$.

With an absence of conventional home-work boundaries, Oxbridge colleges form fascinating backdrops for studying historically-based formal dining conventions within scholarly communities. At the college's center is formal hall, referring to dinners and the dining hall, and reflecting the college's essence as an organization that is simultaneously a place of scholarship and domicile. Oxbridge colleges' formal dining experiences can still be said to involve 'institutional food' (Cook \& Wyndham, 1953), albeit superior, as meals are taken within self-contained organizations that integrate home and work functions. Other such total institutions (Goffman, 1961) include boarding schools and even prisons, where formal eating patterns and conventions vary little despite population changes. College members eating together are likewise shaped by rites of passage and socialization processes. As such, formal hall as sub-cultural ritual involve historically quasi-stationary organizational processes (Lewin, 1975) subject to slight modifications and subtle variations but firmly located within the relatively stable dominant Oxbridge college framework. 


\section{Method and Approach}

Given our interest in understanding Oxbridge's formal hall ritual, our empirical investigation adopted an ethnographic approach. Ethnography "decodes and recodes, telling the grounds of collective order and diversity, inclusion and exclusion..." (Clifford, 1986, p.2). In organization studies, ethnography is used to "uncover and explicate the ways in which people in particular work settings come to understand, account for, take action, and otherwise manage their day-to-day situation" (Van Maanen, 1979, p.540). It is based on systematic and rigorous observation and interviewing, combined with the production of texts that translate the meanings and practices of a cultural group into convincing 'thick descriptions' (Geertz, 1973). This study involves 'opportunistic ethnography' (Reimer, 1977), a method of studying settings where researchers are already members. It departs from more traditional ethnographic forms which study the subject positions of distinctive 'others' (WrayBliss, 2003).

\section{Data Collection, Reflexivity and the Ethnographic Frame}

In total, 22 formal halls staged in ten different colleges ${ }^{4}$, three founded post-war and seven in the $19^{\text {th }}$ century or earlier, were used over 24 months as the basis of observations and analysis. The first author conducted the majority of the fieldwork, making near-contemporaneous notes and reflective accounts in a diary used to explore subjective experiences, interactions and behaviors along with more 'traditional' observations. This resulted in over 150 pages of text, following dinners of typically two-hours duration, excluding post-prandial customs outside the dining hall. Notes on conversations and interactions with others during the meal were included. Reflective, autoethnographic commentaries were documented in detail, highlighting the first author's own experiences and reactions. The second author acted as a 'critical friend' (Costa \& Kallick, 1993) by adding his own reflections through a meaningful and in- 
depth appreciation of the context of the work. He had previously had college membership and attended many formal halls. Thus some of his experiences are used as additional descriptive examples of the ritual to complement the more detailed ethnographic commentaries of the first author. As a result, experience of college membership by both authors provided sufficient familiarity for supporting data analysis and interpretation.

The findings are based on emergent interpretations grounded in the data itself. The data collection was not approached with defined theoretical ideas but sought emergent insights, to be compared with the literature during analysis. The approach combines ethnographic interviewing, conversations and autoethnography to generate rich understandings of formal hall's reality for its participants. Thus participant obervation and reflection formed the core inductive method. The first author actively positioned herself alongside other ritual participants (Alvesson \& Sköldberg, 2000; Holland, 1999). Research authority stems from involvement and embeddedness in the ritual, thereby framing data construction and interpretation (Hatch, 1996). The researcher's 'voice' is thus endemic in data production and subsequent narration (Putnam, 1996).

Interactions took place with a range of ritual participants including undergraduate and postgraduate students, college faculty, other academics, porters, and waiting staff. In addition to observations and/or conversations with these participants during formal hall, six pre-arranged one-to-one ethnographic interviews were held with college members (two college faculty, three students and one alumnus) away from the event. We also chose to carry out six ethnographic interviews with other academics on their views on college dinners. The latter were not college members but were invited occasionally to attend formal hall, thus providing views from more peripheral and/or excluded individuals. The first author wrote interview notes, subsequently reflecting upon these in the field diary. Quotations used are drawn from these notes and diary reflections.

As the research involved data from ethnographic interviews, issues of consent and anonymity are important considerations. Interviewees were always informed about the 12

Di Domenico, M. \& Phillips, N. (2009) 'Sustaining the Ivory Tower: Oxbridge Formal Dining as Organizational Ritual'. Journal of Management Inquiry, 18 (4), pp. 326-343. doi: 
study. This was also the case with ethnographic in situ conversations with diners seated close to the researcher. Indeed, this was often used as a conversation topic or 'icebreaker' to facilitate discussions. Respect for privacy was maintained and all individual participants and colleges are kept confidential to ensure anonymity.

College membership facilitated greater understanding of the organizational contexts framing both dinners and diners (Alvesson, 2003). The process of in-depth immersion in the setting, and interactions with significant others before, during and after formal dinners, was facilitated by an inclusive research approach not restricted solely to dining events. Active and regular participation in college dining pre-dating research participation acted as a necessary preparatory period. Prior to and during the study, both researchers had multiple dealings with various aspects of college life. These included teaching and student supervisions, as well as participation in college events and sports such as rowing.

\section{Analysis and Representation}

Our theoretical arguments, although empirically grounded, relate the 'ideal-typical' (Weber, 1949) formal hall to broader action structures. We are concerned with the ritual's importance to intra and inter-organizational processes, rather than the elucidation of subtle differences in dining rituals per se. The analysis of ethnographic observations involved multiple close readings of the data followed by thematic coding to reveal emergent themes (Miles \& Huberman, 1994). Collated text was marked and grouped using themes emerging from initial familiarization. All the excerpts and event summaries presented are the outcome of this synthesis. The analysis essentially involves data reduction and interpretation by means of thematic coding and cross-case comparison, termed as 'framework analysis' (Ritchie \& Spencer, 1994). This comprised four main stages; data familiarization; identification and application of thematic codes; synthesis of coded text; interpretation. This process is facilitated by MaxQDA, a qualitative analysis software package for data management, coding and retrieval. 
Based on our analysis and emergent data coding, the ritualized dimensions of the dining events gave rise to the following dimensions: (1) script sequencing, norms and enactment; (2) setting, artifacts and staging; (3) socio-political and pedagogic facets; and (4) stakeholders and external relations. These categories structure our findings and frame the 'thick descriptions' and data excerpts presented. The next part of the article presents our findings. This explores the experience and effect of interactions and behaviors at formal hall. This is split into four sections that correspond to the dimensions outlined above. The first three dimensions focus on its staging and purpose within the immediate college setting. The final dimension reviews its role in relation to interactions with stakeholders at wider institutional and societal levels.

\section{FINDINGS:}

\section{DINING AS RITUAL AND ALLEGORY OF THE ELITE ACADEME}

We present and theorize our findings in relation to formal hall ritual's emergent attributes identified from the study. These are its key dimensions, as well as the effects of, and transgressions against, each of these dimensions.

The concept of 'transgressions' requires unpacking and discussion. The fieldwork uncovered transgressions that caused varying degrees of strain within the ritual. From our analysis we define 'transgression' as an introduced action or event that alters, modifies, violates or expresses opposition or resistance to ritual norms. We argue that there is a continuum from 'lower-order' to 'higher-order' transgressions. Those tending towards the former, although more subtle in effect, still change, alter or modify the ritual. Due to formal hall's very long history, ritual permutations are displayed in colleges which nevertheless adhere to the same overall principle of formal communal feasting. Therefore, due to alterations or variations in tradition and ritual enactment, those tending to be 'lower-order' rarely threaten the ritual markedly as they are easily amalgamated into dominant norms, even serving to reinforce formal hall's overall power and reach. On the other hand, those approaching 'higher order' involve more explicit resistance strategies or challenges to the ritual. These are more difficult to diffuse, and thus have the potential to threaten the ritual. 
Our findings give examples of these different transgressions. We also summarize our findings in Table 2 in order to better explicate our analysis and interpretations. The discussion contained here, and the contents of Table 2, are interwoven with data and corresponding empirical examples as evidence of these key dimensions, and their corresponding effects and the actions/ events that transgress the ritual's existing norms.

\section{INSERT TABLE 2 HERE}

\section{Script Sequencing, Norms and Enactment}

The 'formal dining' script is examined as a sequence of ritualized events enacted by organizational players, creating social cohesion, and ensuring historical continuity through long-standing organizational norms, thus preserving ritual exclusivity. The ritual script and sequencing of formal hall follows a highly prescribed format, although slight variations exist according to specific colleges. Colleges cannot generally hold formal hall outside term-time. Older colleges tend to have greater formality and separation between faculty and students. On certain celebratory dates, dishes reflect 'themes' such as Burns' Night and St. Patrick's Day. Special formal dinners are also staged within the college calendar relating to social clubs, sporting and alumni events. Rather than wearing gowns ${ }^{5}$, formal hall's normal attire, these are often 'black tie' events with women in evening dresses and men in tuxedos.

Generally college meals begin with the College Master saying grace before other attendees are seated. A three-course meal with wine is served, followed by coffee. The college norm is to finish with port or dessert-wine and fruit, although participant numbers dwindle by this optional stage. The following is a typical script:

I swapped my coat for my gown and entered the senior combination room. The fellows were all there. After some cordial pleasantries, we then processed into the dining hall and stood behind our chairs waiting obediently for the Master to say 
grace. It was a Thursday evening during Michaelmas term, and one of the many formal hall dinners being held in various colleges throughout the University. Separated from the faculty who were seated at High Table, the chatter of undergraduates was hushed by the sound of the gong administered by the Porter. "Benedic, Domine, nos et dona tua, quae de largitate tua sumus sumpturi" pronounced the Master, and everyone responded by taking their seats to dine (Extract from field diary).

The college dinner has its own rules and etiquette routines, elements codified into ritual. Enacting these behaviors coheres participants through sacredness of custom. Thus their status and legitimacy are not questioned. However, 'novices' easily make mistakes and, once after a college meal, the first author was 'pulled-up' for inadequate awareness of convention;

The meal was over and the table had been cleared and re-laid for port and fruit. I picked up the decanter that was placed on the table and offered it to a fellow on my right. At that point the fellow on my left leaned over and whispered that it was improper to "pass the port in an anti-clockwise direction". The same individual, obviously concerned by that point that yet further improprieties would be committed, pointed out in a kindly tone that the larger glass was intended for sweet wine and the smaller one for port. Feeling exposed, I decided that it would be safer to opt for neither beverage (Extract from field diary).

Formal hall's scripting also includes parts played by other supporting players who, although not diners, are integral to its enactment. The servers, porters and kitchen staff do not experience the meal from the same standpoint as those dining. Their experience is not a hybridized mix of business and pleasure, but part of an ordered workplace. Nevertheless, they are invested with the stewardship of the event, acting as guardians of its inherent nature and value. The various roles of those 'background actors' are integral not only to the ritual's script sequencing and performance norms, but also to the smooth daily running of the whole college ${ }^{6}$. 


\section{Effects and transgressions}

The script and sequencing of formal hall follows highly prescribed formats. Social cohesion is maintained via normative performances and etiquette rules. Formal hall perpetuates historical continuity via prescribed script sequencing. Therefore, customs including dress code, dining etiquette, and pre- and post-dinner conventions serve to support specific norms through repetition of performance rituals. These elements of the ritual's enactment affect secondary socialization processes whereby newcomers and existing members are expected to conform. In our study's context, we define social cohesion as the ongoing process of interaction among members of an organization with shared interests, aims and values. We argue that this is a particular effect or outcome of the dimension of script sequencing, norms and enactment as these act as bonds or "glue", bringing members together at a particular time and location, thereby enhancing social order and identification. This is evident by the fact that the majority of participants positively embrace formal dining's significance as an Oxbridge tradition, relishing enacting the nuances of its scripting;

I talked about convention and tradition over dinner this evening with the fellows sitting on either side and opposite me. They all agreed that Oxbridge and formal hall were inseparable. A fellow sitting next to me explained he regarded formal hall as crucial for students and faculty alike. He went as far as to say that members "owed" it to the college and to each other to attend regularly in order to show solidarity. College members strengthen its constitution by joining together in a regular explicit display of shared belonging (Extract from field diary).

The issue of class in this respect may be significant for certain actors. Students from working class backgrounds lacking prior exposure to conventions similar to those of formal hall describe initially feeling gauche or uneasy with the required conventions and formality of enactments, rather than resenting the ritual. This is overcome through inclusion, socialization and regular participation. Once entry into the Oxbridge system is granted, membership is bestowed upon the individual and transcends class or 
background, despite class-based protocols not being suspended as evidenced by formal hall. Rather, members must learn and operationalize these protocols. This threat tends to be 'lower order' in nature as the potential danger of members not participating or identifying with it is counteracted. Indeed, methods used denote 'apprenticeship' into scholastic traditions, as expressed by a student:

"I have to admit, I didn't really feel that I quite fitted in at first. Well, I'm not used to dinners and gowns and that type of thing. My school wasn't really like that. I suppose after a while you just relax a little and don't worry so much. I was afraid that I might stand out like a sore thumb but everyone was really nice. I don't feel that way anymore. I don't feel awkward or anything. It's a kind of social training I suppose, as well as an educational one. I'm really lucky" (Extract from ethnographic interview).

Knowledge of formal hall's conventions confirms the diner's legitimacy, whereas lack of knowledge causes such legitimacy to be questioned to the transgressor's discomfort. Lack of conformity threatens social cohesion which is strained by such a transgression, although some deviations are permitted by privileged (temporary) members. For instance, certain participants, guests at a particular meal or visiting scholars, as temporary privileged members, tend to be unencumbered by normal expectations;

I was a bit surprised that a visiting scholar to the college seemed not to have to conform to the normal dress code. He sat at high-table without wearing an academic gown. No one remarked on this, however, and the dinner was in all other ways similar to normal (Extract from field diary).

Transgressions against the ritual were observed within historical preservation of tradition. For instance, those we deemed of a 'lower order' include slight variations to script sequencing, norms and enactment according to the specific college and dinner. Colleges differ on specific facets such as days attributed to formal hall and degree of formality beyond the wearing of gowns. Thus, invited guests can dine without gowns. 
Some 'newer' (typically post-war) colleges also permit the saying of grace in English rather than Latin. Subtle variations and deviations from dominant scripts are permitted as they are not disruptive enough to subvert the stable dominant framework of collective formal feasting.

Another practical example of permitted transgression within the scripting of formal hall is derived from the second author's experiences as a professorial fellow of a newer college. As part of his role, he would twice termly be responsible for 'hosting' formal hall jointly with another faculty member. This meant that the presence of the master administering proceedings was not always necessary. Such a role involved welcoming guests, students, and fellows to the event, and administering grace in the master's absence. After dinner, the fellows playing the master's role invite the fellows attending dinner back to the senior combination room for port and coffee.

Transgressions against the ritual's scripting and historically-defined norms may also be orchestrated by certain participants' subversive acts. Stories were told about students acting in ways counter to college formalities;

A former college master described students' pranks at formal hall with amusement and almost a wistful recollection. These involved food fights (typically after fellows had retired from dining hall to senior combination room), drunkenness, wearing shorts and other inappropriate dress underneath their gowns, and hiding college crests and other emblems and placing them in obscure places (Extract from field diary).

Although perhaps initially orchestrated as an overt strategy of resistance through mocking customs, subversive acts such as student pranks and contravening or ridiculing the dress-code were recounted by participants as almost 'mythic events' surrounding the ritual, to be told subsequently to new student cohorts. In time, they become legitimised with threat diffused, thus rendering them of 'lower order' status. Indeed, we argue that such folklore with their repetition adds to formal hall's allure and symbolic quality. Thus, taking an agonistic view of ritual, as well as formal hall's 
cohesive outcomes, these transgressions manifested through the ritual's subversion or contestation illustrate multiple, co-existing voices within ritual elements. However, as they tend to hold a low level of threat and are essentially amalgamated into formal hall's script and routine, the ritual's power dominates, affirming social cohesion and historical continuity, despite allowances for some variation and fluidity. This flexibility within the dominant script further enhances the script's continuity through absorbing sub-scripts. This absorption of possible oppositional elements simultaneously diffuses and weakens their power to threaten the dominant script and the core elements of its ritual enactment by key players.

\section{Setting, Artifacts and Staging}

The college dining halls' spatial characteristics and artifacts often appeared almost theatrical overstatements of symbolic values;

This was one of the ancient colleges I'd wanted to dine in for some time. I took in my surroundings; the high ceilings and old portraits on the walls, which I speculated were possibly of previous Masters or other dignitaries. The effort expended on the presentation was significant. The tables were adorned with large ornate candles. I found the food was not as elaborate as the surroundings but the latter was clearly more important to everyone present (Extract from field diary).

Exclusivity is not just symbolized by the ornate décor and grandeur of the college's setting. Although the physical backdrop and props demarcate the unique quality of formal dining, participation is also selective and presence at the occasion is permitted only as college member or guest. The researcher noted her impressions of the oldest colleges:

I felt almost transformed to another time, another age. It was like being at a medieval banquet. The surroundings felt rather theatrical, like I was playing a part in a play or period drama. I felt seduced by my surroundings, and reflected on the 
privilege of my own participation as well as those who experience its charms routinely as part of their everyday lives (Extract from field diary).

There are many examples of repeated gastronomic events that can be analyzed as ritual, such as annual ceremonial feasts and those marking significant life passages such as graduation lunches or celebratory drinks. Similar to these events, formal hall's validity is maintained through the use of particular symbolic markers and artifacts heralding the importance of social-historical continuity. No individual dish defines the ritual. Rather, there are important and specific identity markers such as wearing gowns and drinking port following dinner, artifacts which differentiate formal hall from luncheons and other less formal events that take place in the same setting. The organizational ritual is nevertheless also defined primarily by its physical location. In other words, the college context is a necessary setting for formal hall, which is bound by its existence. The centrality of the dining hall for the overall fabric of college life was repeatedly observed:

The physical layout almost appeared to posit the dining hall as a focal point. The high ceilings and the décor were impressive, if rather foreboding. Recounting the different occasions that I had been there in the past, it struck me that while befitting the sense of occasion of formal hall or other formal dinners, it had initially felt peculiar to be seated in such a grand setting for a canteen-style luncheon served daily in college (Extract from field diary).

Thus, the dining space itself, although exerting a central pull within the college, is neither static in usage nor symbolic value. This is reflected in the fact that during the day the impressive formal setting doubles as a space for more informal interactions when the stricter conventions of formal hall scripting are suspended.

\section{Effects and transgressions}

Artifacts and staging are central to ritual in terms of both spatial setting and props. In the case of formal hall, the effects of these ritual aspects are to preserve its exclusivity 
and participatory reverence, reaffirming historical norms of social hierarchy and bureaucratic order. For instance, these norms are reaffirmed via certain artifacts and props central to the feast. These include seating arrangements which typically, in older colleges, involve 'high-table' physically and symbolically separating faculty from students.

While formal hall continues to act as central to college life, not all authorized participants attend formal hall as often as permitted. There may be different reasons for this. For instance, some members may choose not to attend formal hall, or reduce the frequency of their attendance, due to feelings of discomfort concerning the formality of the event, or as resistance expressing their criticism of the ritual through non-participation. These transgressions tend to be of a 'higher-order' as, if sufficient numbers protest in this way, the ritual cannot be staged and will experience major disruption as a critical mass of attendees are required. We came across a number of students who expressed unease about the convention due to its scripting and aura of elitism and who restricted their attendance. We did not, however, come across any who had completely stopped attending formal hall for these reasons. This is probably due to the fact that such persons would be difficult to meet and, it is unlikely that students would be at Oxbridge if such strong sentiments were held. Nevertheless, a 'higher order' threat derives from the observation that faculty not resident within the college grounds, or with family and other obligations elsewhere, attend less frequently than those with college rooms ${ }^{7}$. Such fellows have conflicting college and family obligations. However, despite the changing characteristics of fellows, the ritual has essentially survived, and yet has been subject to pressures upon its heritage and monastic character.

It is interesting to note the ways 'newer' post-war colleges create subtle subversions of traditional hierarchical manifestations as some, such as the predominantly postgraduate colleges, do not have 'high-table' and students are seated among faculty members. Indeed, visual displays of opulence are also less marked in the dining halls of 'newer' colleges. This transgression by the latter causes only subtle variations to the dominant script. The introduction of such variations by these colleges may be 
partly due to their lower social status within college hierarchies, their comparative lack of funds, and the era when they were designed and constructed. Nevertheless, with the passing of time, formal hall adapts to the individual life-world of the college in question, whereupon the ritual absorbs and thereby diffuses any initial disruptions caused by changes to setting, artifacts and staging.

\section{Political, Social and Pedagogic Facets}

Formal hall, as an example of an integral ritualistic component of the collegiate model, engrains into its fabric hierarchical conventions and systems of inclusion recognized by college members. It is used as a central organizing facet of college social life both for faculty and students. However, it is also used to orchestrate organizational politics and strategic discussions pertaining to pedagogic and other roles. Information on new academic incumbents, funding opportunities, promotions and other issues relating to work-roles and political structures are frequently exchanged. Remaining informed is a useful feature of inclusion and participation. Therefore, the formal dinner should not be defined as outmoded, self-regarding or deferential. To view it thus negates its highly complex character and political purpose. Akin to a members' club, it straddles formality and sociability with a fluidity contrasting with more defined temporal and spatial boundaries of most higher education institutions and other workplaces. The collegiate model relates to the university's size and complexity by asserting unique identity markers and systems of inclusion benefiting college members, and is a key facet of the college bureaucracy. However, unlike many routine university ceremonials, participation is determined primarily by college organizational membership.

As well as the political significance of these meals in interacting with key individuals and decision-makers, dinners are also an opportunity for participants to relate on a more informal level, discussing holidays, children and other aspects of personal lives: 
Today I spent an hour or more hearing about the social clubs and societies of two students. One was secretary of the rowing club and the other an avid runner. I was also told about the practice of "formal hall swapping" which facilitates interaction with members of other colleges (Extract from field diary relating to ethnographic interviews conducted).

Detailed discussions with students about formal hall revealed that it was "fun", providing them with opportunities to socialize, get "dressed up", and mingle with peers. Students reported that the presence of faculty was neither off-putting nor detracted from their enjoyment.

I purposefully decided not to sit at high table with the other faculty on a number of occasions and instead seated myself with the students at other tables. This way I could talk in a relaxed way with them and get their views. When I asked a group of undergraduates on one occasion how they viewed the staff from where they were sitting there was general agreement that they hardly noticed them and their presence in no way impeded their enjoyment and ability to socialize with their fellow students. One student said the following: "I find it's rather similar to dinners at school. I attended a boarding school before I came here so it's quite normal to have your teachers around. You just take it in your stride and get accustomed to it. I don't really see what the fuss is all about. They're just dinners, but just a bit more formal than you might have at home with your mum and dad" (Extract from field diary).

\section{Effects and transgressions}

As implied by the discussion so far, the effects of formal hall in terms of its political, social and pedagogic facets are many and varied. Student socialization into Oxbridge culture through rituals such as formal hall was found important in terms of the college's internal cohesion and their integration into its everyday social and pedagogic aspects. However, there was an explicit association of the event and its symbolic nature with elite social and educational institutions, denoting class-imbued 24

Di Domenico, M. \& Phillips, N. (2009) 'Sustaining the Ivory Tower: Oxbridge Formal Dining as Organizational Ritual'. Journal of Management Inquiry, 18 (4), pp. 326-343. doi: 
status protocols. These were either criticized in principle by some students or actively embraced by others. Participants identify with rituals in different ways according to their backgrounds and ties to the framing institution. Cohering participants via practical orchestrations such as rituals, illustrates organizational [hegemonic] attempts to shape and control individual-collective processes of identity construction despite evident contestations (Humphreys \& Brown, 2002).

Thus, there were differences of opinion about the ritual's validity. Although it was found that most students agreed that it was useful as an additional socializing mechanism, some were critical, as reflected in a male undergraduate's comments:

"I like coming along very occasionally so as not to be left out of things and just to have something to do with friends I suppose, but I'm not a fan of all the pomp and ceremony. I think it's all a bit nauseating and self-important although I know that's not a popular opinion to have and I can see why we have them. Don't get me wrong there's a lot about college that I think is great and I like socializing as much as anyone else. I just find formal hall all very 'public school' and I'm trying to move away from that. I imagine people without that sort of background would find it really intimidating at first, maybe when they go to their very first formal" (Extract from ethnographic interview).

Nevertheless, the existence of such dissent about convention tends to lower-ordering as ritual participation is generally forthcoming with appreciation for its ability to cohere participants. It became apparent therefore that cohesion is engendered by both the identified dimensions of 'script sequencing, norms and enactment', and 'political, social and pedagogic facets'. Indeed, the ways in which etiquette and class-based protocols underlie formal hall's nature are central to its systems of inclusion and participant identification. Thus, one can appreciate the cross-influences and dynamic inter-relationships among these ritual dimensions whereby they can combine to generate similar effects. 
Formal hall also presented academic faculty an opportunity to share disciplinary knowledge without feeling inhibited by pressures from subject-specific peers and scrutiny from large student audiences. Frequent discussions took place about publication of a recent book or article, and on subjects as diverse as classics, economics and English literature:

I had a fascinating conversation with a Polish academic over dinner about Marxism/critical theory. He seemed pleased by our discussion and scrawled some references on a napkin for my benefit (Extract from field diary).

The cross-disciplinarity of college members distinguished these gatherings from subject-specific events, serving to infuse dinners with both variety and ambiguity. Sturdy, Schwarz, \& Spicer (2006) refer to the political significance of 'off-site' meals and dinner parties as liminal spaces which perpetuate organizational politics and decision-making while allowing informal behavior away from the workplace. Similarly formal hall is used as a key social and political medium. It provides a space for enjoyment allowing also for more formal interactions, information exchange and networking. However, it is integrated into the college's physical fabric and everyday use as a space for the ongoing accomplishment of organizational goals, and as such cannot be divorced from other discourses of action, routines and politicking.

In contrast to the meals and social events performed away from the organization, the college dinner does not suspend organizational routines, codes or hierarchies. The dining ritual creates a sense of identification among participants through broader notions of shared college membership with prescribed norms and scripting. The key criteria for acceptance as a participant in the ritual are a priori links to the college or its members and the ability to enact dining conventions. However, acceptance does not mean equality, as the college hierarchy is ever-present, represented at the dining table through seating practices and class-based protocols (Bourdieu, 1984), deeprooted in tradition and preserved by both diners and servers. These effects may give rise to transgressions against ritual norms, and thus require careful management on a constant basis in order to reduce any potential for adverse impact such as vocal 26

Di Domenico, M. \& Phillips, N. (2009) 'Sustaining the Ivory Tower: Oxbridge Formal Dining as Organizational Ritual'. Journal of Management Inquiry, 18 (4), pp. 326-343. doi: $\underline{10.1177 / 1056492609336482}$ 
criticism. Indeed, the visibility of such elements is used as a mechanism that adds to its evocative nature and persisting appeal for those it embraces.

\section{Stakeholders and External Relations}

Elaborate dinners differentiate the college from its counterparts in terms of status position. Formal hall explicitly displays each college's heritage and power ${ }^{8}$. Formal dining's allure for those external to the college is significant for its endurance. Notions of exclusivity of participation are tied up with esteem invested in the institution's authority. As an extension of the Oxbridge character, formal hall is an established tradition catering for college members and alumni, visiting scholars and invited dignitaries or other "friends" who contribute to the college:

At the end of the meal, the head of the college stood up to give a speech on the successes and efforts of students and fellows that term. He also reminded those who would soon be leaving the college as graduates that ties should be maintained with the college as "life long members" and "friends" (Extract from field diary).

At some meals alumni are in attendance. Such networking is important as they identify strongly with the college and contribute financially and in other ways. The following sentiments were expressed by an alumnus:

"Yes, it's nice to attend college and keep in touch. Of course I receive the college newsletter and things like that but I like to know what's actually going on and still feel part of things. So dinners are a good way of doing that. I live locally after all and run a successful business, so if there's something that I can give back then I will. These students are smart, so it's useful to spot any talent." (Extract from ethnographic interview)

Effects and transgressions 
Formal hall's ritual heralds a tradition somewhat peculiar to Oxbridge. It acts as 'organizational glue' binding together different colleges in a sense of shared tradition and purpose. Nevertheless, formal hall is also a display of social-standing, wealth and influence both within the inter-college system and for external stakeholders.

As was shown by the greater degree of opulence and ceremonial markers, the older, more traditional colleges tend to outdo their newer, poorer contemporaries. Thus the formal dinner displays symbolic organizational rivalries which counter the ritual's cohering role. This causes ambiguities. Bringing these elements to the fore runs parallel to the ritual's cohesive effects by stimulating spectacles of organizational subversion, difference and variation. Nevertheless, these transgressions are diffused by subsuming changes into the ritual, thereby ensuring its survival and even further expansion when new colleges are formed. Moreover, formal hall reflects the wider organizational politics of the Oxbridge system stretching beyond the colleges themselves. As the oldest university institutions, the colleges use ritual to build solidarity among members, creating subtle oppositions to alternative forces, even from university departments and central administration.

In keeping with arguments espoused by the agonistic thesis (Lukes, 1975; Roth, 1995), participation is necessarily selective to retain the core power of ritual exclusivity. This is ensured by guarding customs through obedience to conventions and key members' power to determine which non-members will be introduced and invited to join. A colleague who held a departmental university position for some years but who had only recently been conferred with a college fellowship described how the latter had come about when we interviewed him. Another colleague who was a college member had facilitated this process through introductions to key college officials and attendance at formal hall. This networking was subsequently followed by more bureaucratic processes involved in bestowing the award.

There were individuals who despite working as academics within university departments, had not achieved college membership. This restricted their ability to participate in college dining and other rituals and deprived them of college affiliation 28

Di Domenico, M. \& Phillips, N. (2009) 'Sustaining the Ivory Tower: Oxbridge Formal Dining as Organizational Ritual'. Journal of Management Inquiry, 18 (4), pp. 326-343. doi: $\underline{10.1177 / 1056492609336482}$ 
and identity. 'Excluded' individuals can deny college membership's value, or attempt to gain even temporary entry. Views expressed ranged from regarding college membership as desirable to devaluing it:

I met with a colleague, a post-doctoral researcher, and the topic of conversation turned to college dining. He was not a member of a college and said that sometimes this made him feel "excluded" and "a bit out of things". He said that he was of the impression that it would be more difficult to join a college if one hadn't attended Oxbridge as a student or been employed/ funded specifically by a college. Nevertheless, he was intrigued by the convention of formal hall and somewhat questioning of its academic relevance but nevertheless had always accepted any invitations he had had so far for opportunities of college dining (Extract from field diary relating to ethnographic interview conducted).

Such expressions, mixing resistance with conformity, denote desire for inclusion combined with defiance at control by others, reflecting the place that both convention and resistance have in everyday life. The college acts as a key organizing construct and has integral social, political and bureaucratic purpose. Therefore, despite being members of the university and departments or research centers, by not being college members, individuals are defined as peripheral 'organizational outsiders', at least at college level. Arguably, they lack the additional status and esteem of the 'insider', being obliged to participate in dinners and other college rituals only when invited. They thus hold little threat to the established order. The significance of college membership to the wider institution is demonstrated by the first question that is invariably asked by scholars in university departments and other non-college settings. "What college do you belong to?" Such an identity marker gives important status signification to others. It confers a pedagogic Oxbridge kinship transcending individual college boundaries, perpetuating distinctions between colleges and with excluded non-members.

\section{CONCLUSIONS}


Formal hall ritual is an important routine performed within Oxbridge's organizational fabric as a core symbolic marker and centerpiece of pedagogic living. It reflects the Oxbridge brand and the college's standing. Colleges herald their ancient traditions, values and power through such rituals, and none are more potent than formal communal feasting. Effects also at intra-organizational and wider societal levels are: social cohesion, continuity, reaffirming hierarchical structures, membership exclusivity, relationship-building, information exchange, identity affirmation, and influencing socio-political dynamics.

From a mainly agonistic perspective (see Anand \& Watson, 2004; Lukes, 1975; Roth, 1995), we found evidence of complex dynamics, effects of, and transgressions against, the ritual. The central role of power in imparting systems of inclusion and exclusion which can support, subvert or distort ritual enactment is important in understanding the ritual's effects and orchestration. We conceptualized transgressions on a continuum of 'lower' to 'higher' order. Those of more 'lower order' encapsulate subtler elements that serve initially to disrupt existing ritual elements without threatening the ritual's overall force or power. Nevertheless, such changes lead to the increasing presence of acceptable variations. These over time become subsumed as part of formal hall's traditions. Indeed, they often further empower and uphold its continuity by allowing subtle permutations of action and reaction to be expressed by participants who in doing so affirm the college's identity and their own exclusive membership. 'Higher order' transgressions involve more forceful and explicit strategies of resistance that challenge, disrupt or even threaten the ritual's continuity. These are potentially more damaging to the ritual if they cannot be as easily neutralized or integrated. Complete snubbing of formal hall by college members via non-participation, and overt criticism by core privileged participants, have the potential of endangering the ritual.

It would be simplistic to regard the relationship between ritual dimensions and effects as uncomplicated or linear. Established ritual dimensions and their effects have an underlying fragility due to transgressions that may be introduced to disrupt established norms or violate accepted boundaries and/ or codes. The slowness of 30

Di Domenico, M. \& Phillips, N. (2009) 'Sustaining the Ivory Tower: Oxbridge Formal Dining as Organizational Ritual'. Journal of Management Inquiry, 18 (4), pp. 326-343. doi: 
change within formal hall's solid traditions camouflage what are actually fluid movements involving rupture and repair whereby transgressions are encountered and dealt with. They may even be converted into accepted ritual dimensions, thereby contributing to social cohesion and identity affirmation. Ritual enactment's solidity is thus preserved bulwarking the college against potentially threatening outside forces such as central university administration and departments. College members generally belong to other power orders, although college membership, through ritual enactments, is retained as the historically dominant identity marker of the Oxbridge model. Thus, formal hall ritual effects combine with emergent alterations or transgressions to build solidarity, often in subtle opposition to wider administrative forces and political actors. In this way, formal hall both supports and contests existing social structures. The existing Oxbridge collegiate system can be accused of exclusivity, selectivity and seemingly archaic rituals. It supports the essence of Oxbridge academe and broadens intellectual exposure. The college's formal rituals encourage informal networking among academics from a variety of disciplines. This contrasts with increasing trends in UK higher education towards centralized, controlled, managerialist bureaucracies. Thus the Oxbridge college structure and collegiate autonomy and control, symbolized by college formal dining rituals, can be seen as a positive legacy of older university traditions that resist supra-organizational centralization (Willmott, 1995). However, this rich tapestry may also result in pedagogic elitism and resistance to change.

Unlike studies which found formal organizational codes being suspended by organizational members during shared meals (Sturdy, Schwarz, \& Spicer, 2006), formal college dining actively communicates, orchestrates and perpetuates defined formal conventions. This is because it is intrinsically bounded by context and historical legacy. The event's formality is legitimized by, for example, the dining hall's grand surroundings and the college's opulent physical fabric. Thus, sequencing, artifacts and setting are important. Without these the ritual cannot be performed.

Socio-political aims of participant actors are manifest in formal hall's enactment, underlying its importance in maintaining traditions. Thus, evocative somewhat of 31

Di Domenico, M. \& Phillips, N. (2009) 'Sustaining the Ivory Tower: Oxbridge Formal Dining as Organizational Ritual'. Journal of Management Inquiry, 18 (4), pp. 326-343. doi: 
Foucauldian (1977) imagery, the ritual and its codes enforce order and disciplinary power which impart specific power-knowledge relationships onto core members. This produces a perpetuation of historically-constituted discourses of inclusion/exclusion, adding to the ritual's elitism and its centrality to organizational processes of demarcation and stability. However, college dinners cannot be theorized as a 'liminal' zone between work and home (Turner, 1987), as the meal does not disrupt conventional rules of bureaucratic rationality, nor provide domestic informality. Yet, paradoxically, ease of social interaction is greater than in spaces or times devoted predominantly to work-related/scholarly efforts. Formal hall is a highly formalized and scripted organizational space where the social is inherently at ease with formal conventions through processes of pedagogic hybridity reminiscent of traditional academic life when academic boundaries were far more blurred.

Although the ritual's scripting varies, we argue that its overriding power lies not only in what it produces at the intra-organizational level, but also in its supra-ordinate effects transcending immediate organizational boundaries. It is formal hall's powerful reach that demarcates its unique symbolic quality. Despite the fact that its staging and orchestration are inherently tied to the college's physical location, its symbolism and importance transcend the spatiality of the college's life-world, including former members, often of national and international eminence. Although an integral, enduring part of Oxbridge's history and heritage, like other traditionally-imbued rituals, it achieves its identity-marker status through inter-related processes of continuity and exclusivity. This identity construction, and any subsequent bestowal or denial of participation, becomes the most powerful and enduring of the ritual's tools, ultimately determining its survival and influence.

The concept of excess ceremoniality (Alvesson and Karreman, 2007) is applicable to formal hall, which serves to preserve sacred beliefs in the sanctity, centrality and esteem of the college. Its credibility is vested not in its rationality or efficiency as a model of pedagogic interaction. Rather, the power of formal hall is compounded precisely because it stands out as special, original and elitist. Its almost sacred quality derives from its monastic heritage that affirms its power and exclusivity and the 32

Di Domenico, M. \& Phillips, N. (2009) 'Sustaining the Ivory Tower: Oxbridge Formal Dining as Organizational Ritual'. Journal of Management Inquiry, 18 (4), pp. 326-343. doi: 
privilege of participation conferred upon existing and anticipated 'power elites' (Mills, 1956). The fact that this model has been emulated elsewhere reinforces its authority and the elite structures it supports. As our analysis demonstrates, there are many transgressions that impose strain upon the ritual. However, the ritual's overall power remains intact and potential threats are absorbed and thereby neutralized.

We recognize the setting's uniqueness and the highly individualistic character of formal hall as dining ritual. Few rituals transcend the boundaries of the organization and possess the symbolism and remarkable historical resilience and continuity of formal hall. The Oxbridge formal dining ritual straddles the ritualistic gravitas of cultural and religious ceremony with the everyday identity markers of organizational ritual. Nevertheless, it is similar to other rituals emphasizing shared identity through processes of exclusivity and continuity.

Our study makes important contributions on both theoretical and methodological levels. Embracing sociological perspectives and an ethnographic frame, through the exemplar of formal hall, it demonstrates the importance of formal dining as a symbolic organizational medium reaffirming social structure, order and interaction. Although influenced by elements of functionalist and shared meaning readings of rituals, we found most useful the agonistic view, which we used to examine and critique over time the complex dynamics, effects of, and transgressions against, formal hall norms. We found that the central role of power emerged within mechanisms of inclusion and exclusion subverting, distorting or even supporting ritual enactment. Consequently, the more critical and multi-layered agonistic thesis best encapsulates our exploration of ritual's role and effects. We thereby contribute to an evident conceptual gap and a limited body of work on food and consumption, and organizational rituals specifically, within an agonistic frame.

We extend the limited existing research on food, dining and consumption in organization studies by showing the way in which dining rituals are a significant, although continuously contested, part of the Oxbridge model. We also contribute to broader studies of organizational ritual by demonstrating how these routines and 33

Di Domenico, M. \& Phillips, N. (2009) 'Sustaining the Ivory Tower: Oxbridge Formal Dining as Organizational Ritual'. Journal of Management Inquiry, 18 (4), pp. 326-343. doi: 
events have significant effects of profound value in cohering participants and cementing processes of identification and belonging. However, the longevity and historical gravitas attached to such rituals are significant to its successful achievement of these outcomes. There is not a simple heuristic that can be extrapolated and applied to other organizations seeking these ends through such rituals. Nevertheless, all organizations are imbued with routines, stories, nostalgia and interactions, facets that can be leveraged to bring participants together for the organization's benefit. For an organization not possessing Oxbridge's legacy and symbolism, the formality of the event or its symbolic markers may not matter so much as bringing together regularly organizational members for the purpose of enjoyment.

Thus, although we are careful not to make excessive claims for practical management implications, extrapolations can nevertheless be made about the power of comparable ritual enactments in other organizational environments. Dining rituals and communal feasting are important and endemic features of a plethora of work-related rites, rituals and ceremonies. The invention of tradition through such rituals, whether in newer organizations or those with an older heritage, can help implement and affirm an identity and sense of belonging to its members.

This work has particular relevance for elite dining rituals in other organizations. An example is the Officers' Mess where military decision-makers interact separately from lower-ranking personnel who eat and socialize in their own mess halls. In the British armed forces for instance, higher ranking officers mark exclusive events, such as the Queen's Birthday, through such communal feasting. Another example of the central role of dining ritual for power elites in the UK are the traditional rites for Barristers at the University of London when joining 'Inns of Court', essential before they can be called to the Bar. The process involves 'qualifying sessions', often involving a formal dinner. These are imbued with similar symbolism to Oxbridge College dining.

We argue that research on organizational ritual that examines practices of foodsharing should move beyond rather inward-looking orientations and focus on 34

Di Domenico, M. \& Phillips, N. (2009) 'Sustaining the Ivory Tower: Oxbridge Formal Dining as Organizational Ritual'. Journal of Management Inquiry, 18 (4), pp. 326-343. doi: 
historical processes of action that inform the evolution of ritual and its current manifestations. Insights from our study can be extrapolated to broader critiques of organizational ritual beyond those of food consumption. Organizational rituals are likely to share at least three of the four dimensions manifest in our study, namely script sequencing, norms and enactment; setting, artifacts and staging; and sociopolitical and pedagogic facets. However, the extent to which other rituals display evidence of our fourth dimension, the involvement of stakeholders and external relations, will vary. Future research on organizational ritual could explore this further, looking at ways in which ritualized practices within organizations influence internal and external actors and agencies, and the power and status of the organization.

From a reflexive standpoint, we found the process of ethnographic immersion in the unique context of Oxbridge fascinating, revealing the organizational life world of the elite institution. We include our standpoint from an involvement with participants and setting. Despite the seemingly archaic formal hall performance with vestiges of yesteryear, it continues to hold relevance and acts as a centerpiece in the everyday lives of college members and students, from those intensely proud to those more critical, as well as its links with other institutions of power and influence through its external members. Yet, the uniqueness and historical weight of college ritual, and the many transgressions against it continue to mould its articulation, repetition and ultimate survival. It will certainly continue to adapt to various forces of change, training new recruits from diverse backgrounds to its exclusive orderings, while still adhering to the ancient code of privileged academe. 


\section{NOTES}

${ }^{1}$ The term 'Oxbridge' is an amalgam of the Universities of Oxford and Cambridge. The first known reference to this term was the fictitious university in William Thackeray's (1849) Pendennis. It is commonly used as an adjective (i.e. the 'Oxbridge' character), to imply an elite of high social/intellectual status (OED, 1989).

${ }^{2}$ Formal hall is the common label attributed to formal college dinners, particularly those at either Oxford or Cambridge Universities. The meal is intended for college members (both faculty and students) and their guests, who sometimes abbreviate it to 'Hall' or 'Formal'. These meals are different from daily, often canteen-style, college meals. Colleges hold them at different intervals (some twice a week and others only once a term). There is also variation in terms of tradition, with some colleges requiring the wearing of gowns, or other formal attire, and the saying of grace in Latin typically by the College Master. Some, although generally not the newer colleges, have a High Table upon which fellows and other faculty and their guests dine, while students are seated separately at other tables.

${ }^{3}$ The more recent trend has been for many of the female-only colleges to become coeducational. At the time of writing this article, Cambridge has only two colleges which remain as female-only while Oxford no longer has any exclusively female-only colleges.

${ }^{4}$ The names of the particular colleges that were studied are kept confidential to ensure participant anonymity.

${ }^{5}$ A gown refers to the traditional robe, the basic article of academic dress. It is normal practice for the gown only to be worn as academic garb to formal hall and without the hood and other items which are reserved for graduations and other even more formal events. 
${ }^{6}$ Porters, for instance, adopt an almost sacred charge of maintaining and policing college order. Their role is imbued with tradition, whereby they often act as paternal custodians for student affairs and well-being, and facilitate the organizing of facilities for college members' daily needs.

${ }^{7}$ There are usually guidelines that request that current students and college fellows reside within a certain distance of its grounds in order to facilitate their regular and active participation in the academic and social life of the college.

${ }^{8}$ Although different to formal hall in their regularity, purpose and heightened 'red carpet' grandeur, the annual college 'Ball' is another interesting example of formal dining college 'competition'. Such events involve elaborate displays of food and drink, such as 'champagne fountains', and entertainments, such as acrobats, fireworks and even specialist aeroplane displays. 


\section{REFERENCES}

Adair, G. (1986). Myths and memories. London, UK: Fontana.

Alvesson, M. (2003). Methodology for close up studies: struggling with closeness and closure. Higher Education, 46, 167-193.

Alvesson, M. \& Karreman, D. (2007). Unraveling HRM: Identity, ceremony, and control in a management consulting firm. Organization Science, 18(4), 711-723.

Alvesson, M., \& Sköldberg, K. (2000). Reflexive methodology. London, UK: Sage.

Anand, N., \& Watson, M. (2004). Tournament rituals in the evolution of fields: The case of the Grammy awards. Academy of Management Journal, 47, 59-80.

Aziz, A. (1990). Women in UK universities. In S. Stiver-Lie \& V. E. O'Leary (Eds.), Storming the tower: Women in the academic world (pp.33-46). London, UK: Kegan Page.

Barthes, R. (1972). Mythologies. London, UK: Jonathan Cape.

Barthes, R. (1983). Empire of the signs. London, UK: Jonathan Cape.

Beardsworth, A. \& Keil, T. (1997). Sociology on the menu: An invitation to the study of food and society. London, UK: Routledge.

Bell, C. (1997). Ritual: Perspectives and dimensions. Oxford, UK: Oxford University Press.

Beyer, J. \& Trice, H. (1987). How an organization's rites reveal its culture. Organizational Dynamics, 15(4), 5-24.

Bourdieu, P. (1984). Distinction: A social critique of the judgement of taste. Cambridge, MA: Harvard University Press.

Clifford, J. (1986). Introduction: Partial truths. In J. Clifford \& G. E. Marcus (Eds.), Writing culture: The poetics and politics of ethnography (pp.1-26). Berkeley: University of California Press.

Cook, P. H. \& Wyndham, A. J. (1953). Patterns of eating behaviour: A study of industrial workers. Human Relations, 6(2), 141-160.

Costa, A. \& Kallick, B. (1993). Through the lens of a critical friend. Educational Leadership, 51(2), 49-51. 
Douglas, M. (1972). Deciphering a meal. Daedulus Studio International, 101(1), 6181, reprinted in Douglas, M. (1975). Implicit meanings: Essays in anthropology (pp.249-275). London, UK: Routledge \& Kegan Paul.

Douglas, M. (1986). How institutions think. New York: Syracuse University Press.

Douglas, M. \& Isherwood, B. (1979). The world of goods. London, UK: Routledge.

Durkheim, E. (1965; orig. 1915). The elementary forms of religious life. New York: Free Press.

Elias, N. (1969; orig. 1939). The civilizing process, Vol. I. The history of manners. Oxford, UK: Blackwell.

Finkelstein, J. (1989). Dining out. Cambridge, UK: Polity.

Foucault, M. (1977). Discipline and punish: The birth of the prison. (Trans. A. Sheridan) Harmondsworth, UK: Penguin.

Geertz. C. (1973). The interpretation of cultures. New York: Basic Books.

Goffman, E. (1961). Asylums. New York: Anchor.

Goody, J. (1982). Cooking, cuisine and class: A study in comparative sociology. Cambridge, UK: Cambridge University Press,.

Gronow, J. (1997). A Sociology of taste. London, UK: Routledge.

Harris, S. \& Sutton, R. (1986). Functions of parting ceremonies in dying organizations. Academy of Management Journal, 29(1), 5-30.

Hatch, M. J. (1996). The role of the researcher: An analysis of narrative position in organization theory. Journal of Management Inquiry, 5(4), 359-374.

Holland, R. (1999). Reflexivity. Human Relations, 52(4), 463-481.

Humphreys, M. \& Brown, A. D. (2002). Narratives of organizational identity and identification: A case study of hegemony and resistance. Organization Studies, 23(3), 421-447.

Kunda, G. (1992). Engineering culture: control and commitment in a high-tech corporation. Philadelphia: Temple University Press.

Lévi-Strauss, C. (1966). The culinary triangle. Partisan Review, 33, 586-595.

Lévi-Strauss, C. (1969). The Raw and the cooked: Introduction to a science of mythology: 1. New York: Harper and Row.

Lewin, K. (1975). Field theory in social science: Selected theoretical papers. Westport, CT: Greenwood. 
Lukes, S. (1975). Political ritual and social integration. Sociology, 9, 289-308.

Marshall, D. (2005). Food as ritual, routine or convention. Consumption, Markets and Culture, 8(1), 69-85.

Miles, M. \& Huberman, A. (1994). Qualitative data analysis: A sourcebook of new methods. London, UK: Sage.

Mills, C. W. (1956). The power elite. New York: Oxford University Press.

Oxford English Dictionary. OED Online. J.A. Simpson \& E. S. C. Weiner (Eds.), 2nd ed. Oxford University Press, 1989. 14 Apr. 2006, http://dictionary.oed.com/cgi/display/50168644

Pettigrew, A. (1979). On studying organizational cultures. Administrative Science Quarterly, 24(4), 570-581.

Putnam, L. L. (1996). Situating the author and text. Journal of Management Inquiry, 5(4), 382-386.

Reimer, J. W. (1977). Varieties of opportunistic research. Urban Life, 5, 467-477.

Ritchie, J. \& Spencer, L. (1994). Qualitative data analysis for applied policy research. In A. Bryman and R. Burgess (Eds.), Analysing qualitative data (pp. 173-194). London, UK: Routledge.

Rook, D. W. (1985). The ritual dimension of consumer behavior. Journal of Consumer Research, 12(3), 251-264.

Rosen, M. (1985). Breakfast at Spiro's: Dramaturgy and dominance. Journal of Management, 11, 31-48.

Rosen, M. (1988). You asked for it: Christmas at the bosses' expense. Journal of Management Studies, 25(5), 463-480.

Roseberry, W. (1996). The rise of yuppie coffees and the reimagination of class in the United States. American Anthropologist, 96(4), 762-775.

Roth, A. (1995). Men wearing masks: Issues of the description in analysis of ritual. Sociological Theory, 13, 201-227.

Siskind, J. (1992). The invention of Thanksgiving: A ritual of American nationality. Critique of Anthropology, 12(2), 167-191.

Sharpe, T. (1974). Porterhouse blue. London, UK: Secker \& Warburg.

40

Di Domenico, M. \& Phillips, N. (2009) 'Sustaining the Ivory Tower: Oxbridge Formal Dining as Organizational Ritual'. Journal of Management Inquiry, 18 (4), pp. 326-343. doi: $\underline{10.1177 / 1056492609336482}$ 
Stiver-Lie, S. (1990). The juggling act. In S. Stiver-Lie \& V. E. O’Leary (Eds.), Storming the tower: Women in the academic world (pp. 108-128). London, UK: Kegan Page

Sturdy, A., Schwarz, M. \& Spicer, A. (2006). Guess who's coming to dinner? Structures and uses of liminality in strategic management consultancy. Human Relations, 59(7), 1-32.

Trice, H. \& Beyer, J. (1984). Studying organizational cultures through rites and ceremonials. Academy of Management Review, 9(4), 653-669.

Trice, H., Belasco, J. \& Alutto, J. (1969). The role of ceremonials in organizational behavior. Industrial \& Labor Relations Review, 23(1), 40-51.

Turner, V. The ritual process. (1969). New York: Aldine de Gruyter.

Turner, V. (1987). Betwixt and between: The liminal period in rites de passage. In L. Mahdi, S. Foster \& M. Little (Eds.), Betwixt and between: Patterns of masculine and feminine initiation (pp.3-19). La Salle, IL: Open Court.

van den Berghe, P. L., Alabi, P., Nuttney, C. M., Olori, P. \& Sonaike, A. K. (1973). Power and privilege at an African University. London, UK: Routledge \& Kegan Paul,.

Van Maanen, J. (1979). The fact of fiction in organizational ethnography. Administrative Science Quarterly, 24: 539-550.

Visser, M. (1993). The rituals of dinner: The origins, evolution, eccentricities, and meaning of table manners. London, UK: Penguin.

Walton, J. (1990). Fish and chips and the British working class, 1870-1930. Journal of Social History, 23, 243-266.

Warde, A. \& Martens, L. (2000). Eating out: Social differentiation, consumption and pleasure. Cambridge, UK: Cambridge University Press.

Weber, M. (1949). The methodology of the social sciences. (Trans. E. A. Shils \& H. A. Finch) New York: Free Press.

Willmott, H. (1995). Managing the academics: Commodification and control in the development of university education in the UK. Human Relations, 48(9): 9931027.

Wray-Bliss, E. (2003). Research subjects/ research subjections: Exploring the ethics and politics of critical research. Organization, 10(2): 307-325.

Di Domenico, M. \& Phillips, N. (2009) 'Sustaining the Ivory Tower: Oxbridge Formal Dining as Organizational Ritual'. Journal of Management Inquiry, 18 (4), pp. 326-343. doi: 
Di Domenico, M. \& Phillips, N. (2009) 'Sustaining the Ivory Tower: Oxbridge Formal Dining as Organizational Ritual'. Journal of Management Inquiry, 18 (4), pp. 326-343. doi: 


\begin{tabular}{|c|c|c|c|}
\hline & Ritual Event & Explicit Role of Ritual & Ritual Outcomes and Effects \\
\hline Rosen (1985) & Business breakfast meeting & $\begin{array}{l}\text { Marks organizational } \\
\text { successes/performance. }\end{array}$ & $\begin{array}{l}\text { - Exchange of information } \\
\text { - Reinforces social/organizational order and recreates the } \\
\text { bureaucratic power order } \\
\text { - Recognition of organizational/member achievements } \\
\text { - Instrument of social/political control. } \\
\text { - Continuity of organizational processes }\end{array}$ \\
\hline $\begin{array}{l}\text { Harris \& } \\
\text { Sutton (1986) }\end{array}$ & $\begin{array}{l}\text { Parties, picnics and dinners } \\
\text { in dying organizations }\end{array}$ & $\begin{array}{l}\text { Marks the closure ('death') of an } \\
\text { organization. }\end{array}$ & $\begin{array}{l}\text { - Exchange of information } \\
\text { - Confirms impending closure - increases stakeholder acceptance } \\
\text { - Recognition of organizational/member achievements } \\
\text { - Guilt assuagement } \\
\text { - Mutual conferral of emotional support }\end{array}$ \\
\hline Rosen (1988) & $\begin{array}{l}\text { Annual office Christmas } \\
\text { party }\end{array}$ & $\begin{array}{l}\text { Celebrates Christmas and allows } \\
\text { informal gathering of co- } \\
\text { workers. }\end{array}$ & $\begin{array}{l}\text { - Reinforces social/organizational order } \\
\text { - Instrument of social/political control via synthesis of work and } \\
\text { leisure, business and play. Counters notion of a solely rational, } \\
\text { cold organization through fun and amiable celebration. } \\
\text { - Relationship-building } \\
\text { - Continuity of organizational processes by instilling meaning } \\
\text { and legitimizing existing order, structure and realities. }\end{array}$ \\
\hline $\begin{array}{l}\text { Sturdy et al. } \\
(2006)\end{array}$ & $\begin{array}{l}\text { Business dinners held } \\
\text { outside the organization } \\
\text { (e.g. at the CEO's home, a } \\
\text { pizza restaurant, or an up- } \\
\text { market restaurant). }\end{array}$ & $\begin{array}{l}\text { Permits organizational members } \\
\text { to meet with consultants as part } \\
\text { of consultancy strategy projects. }\end{array}$ & $\begin{array}{l}\text { - Exchange of information about historical/critical issues } \\
\text { - Exploring/shaping political dynamics } \\
\text { - Relationship-building } \\
\text { - Testing out and advocating particular approaches. } \\
\text { - Rational routines of organizational working lessened, although } \\
\text { core organizational hierarchy and divisions remain. }\end{array}$ \\
\hline
\end{tabular}

Table 1: Works focusing on food and dining as ritualized practice within the organization, relating to existing organizational members. 


\begin{tabular}{|c|c|c|c|}
\hline Key Dimension & $\begin{array}{l}\text { Ritual Effects/ } \\
\text { Outcomes }\end{array}$ & $\begin{array}{c}\text { Transgressions } \\
\text { against ritual } \\
\text { norms }\end{array}$ & $\begin{array}{l}\text { Generation of Effects/Evident Transgressions and } \\
\text { Corresponding Illustrative Empirical Evidence }\end{array}$ \\
\hline \multirow[t]{3}{*}{$\begin{array}{l}\text { (1) Script } \\
\text { sequencing, } \\
\text { norms and } \\
\text { enactment }\end{array}$} & $\begin{array}{l}\text { Social } \\
\text { cohesion via } \\
\text { prescribed } \\
\text { norms }\end{array}$ & $\begin{array}{l}\text { Permitted } \\
\text { disruptions by } \\
\text { privileged } \\
\text { (temporary) } \\
\text { members }\end{array}$ & $\begin{array}{l}\text { Effect: Ritual script and sequencing of formal hall follows highly prescribed format. } \\
\text { Social cohesion maintained via normative performance of behavior/etiquette rules - } \\
\text { observed notable sequencing (core generic features) of dining ritual. These rites of } \\
\text { passage are socialization processes, whereby newcomers and existing members are } \\
\text { expected to conform to norms. Knowledge of conventions confirms members' } \\
\text { legitimacy. Lack of knowledge results in legitimacy being questioned as lack of } \\
\text { conformity threatens cohesion. } \\
\text { Transgression: Invited guests not burdened with the same expectations of } \\
\text { conformity. }\end{array}$ \\
\hline & \multirow[t]{2}{*}{$\begin{array}{l}\text { Historical } \\
\text { continuity via } \\
\text { repetition of } \\
\text { ritual } \\
\text { performance }\end{array}$} & $\begin{array}{l}\text { Variation of } \\
\text { tradition }\end{array}$ & $\begin{array}{l}\text { Effect: Historical continuity via prescribed script sequencing - e.g. dress code, } \\
\text { dining etiquette, pre and post-dinner conventions. } \\
\text { Transgression: Slight variations exist according to specific college and date of } \\
\text { dinner. Colleges differ on facets e.g. days attributed to formal hall; degree of } \\
\text { formality beyond wearing of the gown. Invited guests may dine without gowns. } \\
\text { Some 'newer' (typically post-war) colleges permit saying of grace in English rather } \\
\text { than Latin. Subtle variations permitted not being disruptive enough to subvert } \\
\text { relatively stable dominant framework of collective ritual enactment of formal } \\
\text { feasting. }\end{array}$ \\
\hline & & $\begin{array}{l}\text { Participants' acts } \\
\text { of subversion }\end{array}$ & $\begin{array}{l}\text { Effect: Historical continuity via prescribed script sequencing - e.g. dress code, } \\
\text { dining etiquette, pre and post-dinner conventions. } \\
\text { Transgression: Students sometimes act in ways that are counter to ritual's goals and } \\
\text { intentions e.g. getting drunk, food fights, playing pranks such as wearing shorts } \\
\text { underneath gowns, poking fun at authority figures. Not observed directly - collated } \\
\text { as stories surrounding the ritual. }\end{array}$ \\
\hline (2) Setting, & Reaffirms social & Subversion of & Effect: Perpetuates routine and bureaucratic order. Social hierarchy affirmed via \\
\hline
\end{tabular}

Di Domenico, M. \& Phillips, N. (2009) 'Sustaining the Ivory Tower: Oxbridge Formal Dining as Organizational Ritual'. Journal of Management Inquiry, 18 (4), pp. $326-$ 343. doi: $10.1177 / 1056492609336482$ 


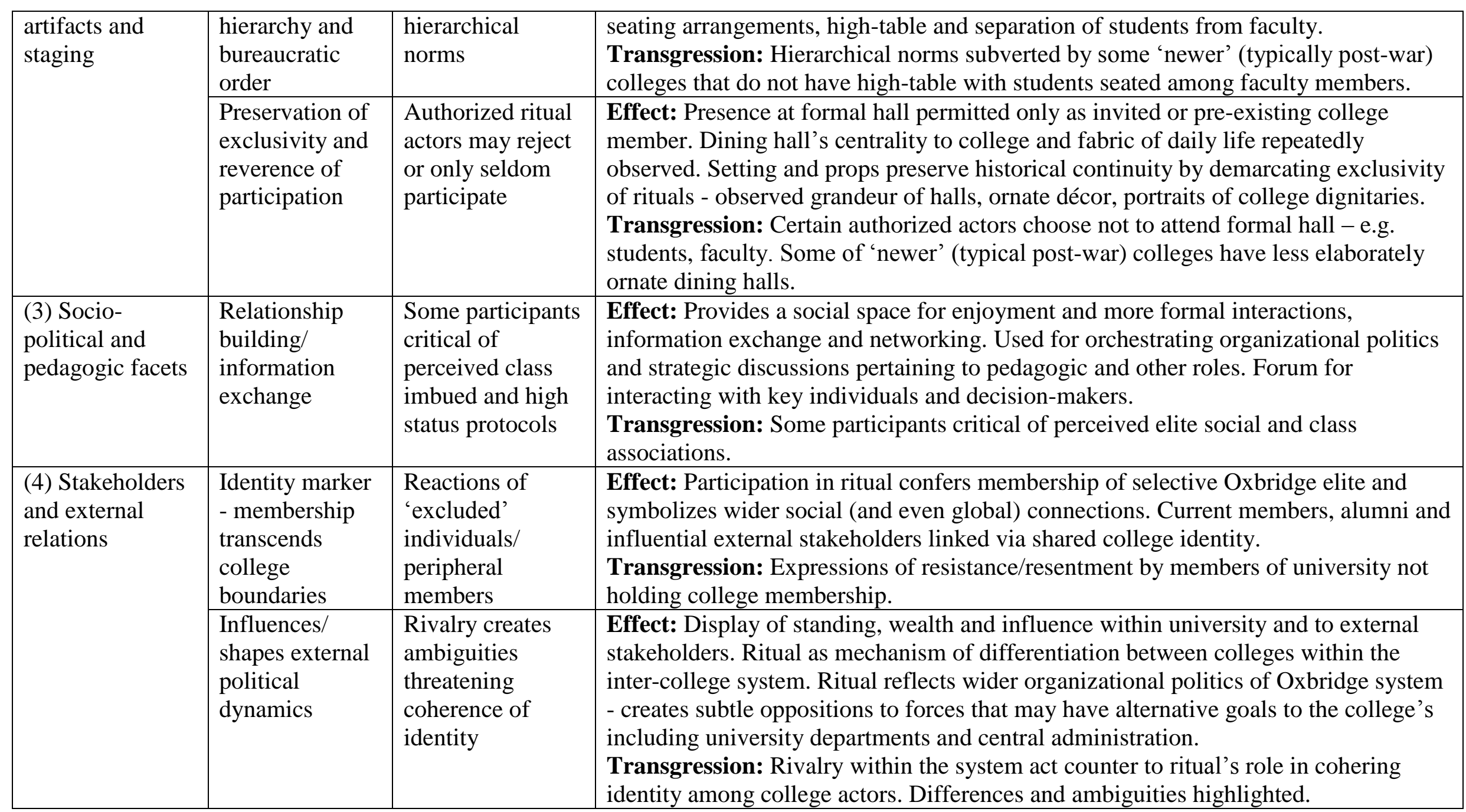

Table 2: Oxbridge formal hall: Dining ritual elements mapped against empirical evidence.

Di Domenico, M. \& Phillips, N. (2009) 'Sustaining the Ivory Tower: Oxbridge Formal Dining as Organizational Ritual'. Journal of Management Inquiry, 18 (4), pp. $326-$ 343. doi: $10.1177 / 1056492609336482$ 
